\title{
Brace Management in Adolescent Idiopathic Scoliosis
}

\author{
Jonathan R. Schiller MD, Nikhil A. Thakur MD, \\ Craig P. Eberson MD
}

Published online: 30 May 2009

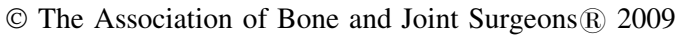

\begin{abstract}
Skeletally immature patients with adolescent idiopathic scoliosis are at risk for curve progression. Although numerous nonoperative methods have been attempted, including physical therapy, exercise, massage, manipulation, and electrical stimulation, only bracing is effective in preventing curve progression and the subsequent need for surgery. Brace treatment is initiated as either full-time (TLSO, Boston) or nighttime (Charleston, Providence) wear, although patient compliance with either mode of bracing has been a documented problem. We review the natural history of adolescent idiopathic
\end{abstract}

Each author certifies that he or she has no commercial associations (eg, consultancies, stock ownership, equity interest, patent/licensing arrangements, etc) that might pose a conflict of interest in connection with the submitted article.

This work was performed at the Department of Orthopaedics, The Warren Alpert Medical School of Brown University and Rhode Island Hospital, Providence, RI.

J. R. Schiller, N. A. Thakur, C. P. Eberson

Department of Orthopaedics, The Warren Alpert Medical School of Brown University, Providence, RI, USA

J. R. Schiller

e-mail: jschiller@lifespan.org

C. P. Eberson

e-mail: ceberson@Lifespan.org

J. R. Schiller, N. A. Thakur

Rhode Island Hospital, Providence, RI, USA

C. P. Eberson $(\bowtie)$

Division of Pediatric Orthopaedics, Department of Orthopaedics, Brown Alpert Medical School/Rhode Island Hospital, 2 Dudley Street, Providence, RI 02905, USA

e-mail: ceberson@Lifespan.org

C. P. Eberson

Hasbro Children's Hospital, Providence, RI, USA scoliosis, identify the risks for curve progression, describe the types of braces available for treatment, and review the indications for and efficacy of brace treatment.

Level of Evidence: Level IV, therapeutic study. See the Guidelines for Authors for a complete description of levels of evidence.

\section{Introduction}

The Scoliosis Research Society (SRS) has defined adolescent idiopathic scoliosis as occurring in patients 10 years or older with an idiopathic structural lateral curve of at least $10^{\circ}$ measured with the Cobb technique and vertebral rotation on a standing longitudinal radiograph of the spine combined with asymmetry on forward bending [28]. It is seen in $1 \%$ to $3 \%$ of the adolescent population, more commonly in girls and, as suggested by the name, has no known etiology. This definition provides a starting point for treatment decisions in the growing spine. Left untreated in the growing child, numerous studies have demonstrated the negative long-term prognosis a progressive curve fosters into adulthood, including back pain, pulmonary compromise, cor pulmonale, psychosocial effects, and even death $[8,9,43,54-56]$. Curve progression is the most important factor in the natural history of idiopathic scoliosis. The risk of curve progression in idiopathic scoliosis has been associated with factors that predict potential remaining spinal growth; therefore, skeletally immature patients with idiopathic scoliosis and major curves are at risk for progression and warrant some form of treatment [3, 4, 29, 57].

Bracing has been the mainstay of nonoperative treatment for idiopathic scoliosis for nearly 50 years. However, because bracing has not gained complete acceptance, 
numerous other treatment modalities have been attempted, including electrical stimulation, biofeedback, manipulation, physical therapy, and exercise [10]. Although a complete discussion of these modalities is beyond the scope of this article, convincing evidence of their effectiveness does not exist. Although Goldberg reported similar surgery rates for unbraced patients compared with braced patients [14, 15], other studies demonstrate bracing is an effective nonoperative treatment modality preventing curve progression compared with no bracing or treatment with electrical stimulation [32, 44].

We reviewed three core areas of the nonoperative (bracing) treatment of patients with idiopathic scoliosis: (1) the natural history of idiopathic scoliosis and risk factors associated with curve progression; (2) the various types of braces and the efficacy of each brace treatment in an evidenced-based approach; and (3) the indications for brace treatment with respect to the type of brace and wear schedule, including our recommendations.

\section{Search Strategy and Criteria}

To review the literature regarding the topic of bracing in adolescent idiopathic scoliosis, we used multiple search engines, including Ovid ${ }^{\circledR}$, MedLine ${ }^{\circledR}$, and PubMed ${ }^{\mathbb{R}}$, using the search string "Brace OR Bracing" AND "Adolescent Idiopathic Scoliosis." We searched for every article available in the literature without restriction of publication date and language of publication. We identified 464 citations. We eliminated inappropriate articles comparing bracing with surgical treatment and brace treatment as an adjunct to surgical treatment because the scope of this article was to evaluate bracing as the only mode of treatment. Additionally, we eliminated articles on brace treatment in patients with scoliosis other than adolescent idiopathic scoliosis. Bracing technique articles and other unrelated studies were eliminated as well, except those for historical purposes, leaving 75 citations. Currently, there is no standard for reporting results on bracing studies; thus, we have included all 75 of the citations for full review.

\section{Natural History}

To determine the need for treatment of scoliosis, it is important to understand the natural history of curve progression. Progression is defined by either a $5^{\circ}$ or $10^{\circ}$ change in curve magnitude, depending on the initial curve magnitude, on a standing radiograph [28]. The two key factors in curve progression are the size of the curve at the initiation of bracing and the amount of spinal growth remaining. According to both Bunnell [3] and Lonstein and
Carlson [29], nearly $70 \%$ of patients with a Risser sign of 0 progressed greater than $5^{\circ}$ for curves between $20^{\circ}$ and $30^{\circ}$. Weinstein and Ponseti [55] followed curves for an average of 40 years and nearly $70 \%$ of curves measuring a minimum of $30^{\circ}$ progressed after skeletal maturity. Similarly, Nachemson and Peterson [32] demonstrated 66\% of observed patients with idiopathic scoliosis curves measuring $20^{\circ}$ to $35^{\circ}$ progressed $6^{\circ}$. Karol et al. [23] found $32 \%$ of boys presenting with a curve of at least $25^{\circ}$ and all Risser stages progressed $10^{\circ}$ or more. Boys tend to have curves that progress beyond Risser 4 into late adolescence, whereas girls' growth has begun to decelerate by this time.

Curve progression is also related to curve pattern, whereby double curves progress more than single curves with the least amount of progression seen in single lumbar curves $[3,29]$. Large curves $\left(30^{\circ}-40^{\circ}\right)$ will progress more than small curves $\left(20^{\circ}-29^{\circ}\right)$ and will continue to progress even after skeletal maturity has been reached should the curve reach a large enough magnitude [3, 4, 38, 55]. Females progress more than males as evidenced by larger curves seen more often in females compared with males $[3,4,55]$.

Determining maturity and risk of progression may be achieved with several methods. Tanner staging, although quite familiar to pediatricians, is often not accurately gauged by orthopaedic surgeons. Girls typically reach peak height velocity (PHV), the maximum increase in growth rate during the adolescent growth spurt, 18 to 24 months earlier than boys, typically between Tanner stages 2 and 3 , whereas boys do so between stages 3 and 5 [45-47]. This phase of growth represents a period of increased risk of curve progression. Menarche can be useful in girls, although it is reached most commonly after peak height velocity and can be variable. Measuring height at each visit is important; however, because growth is often in spurts, a period of substantial growth may be missed and PHV determined only in retrospect. The most commonly used radiographic marker is the Risser sign and this can be determined without the need for additional radiographs if the iliac crest is routinely included on spinal radiographs. The probability of progression has been calculated by both Lonstein and Carlson [29] and Nachemson and Peterson [32] using curve magnitude, and Risser sign and age, respectively, and both authors concluded the younger the child, measured as Risser sign or age, and the larger the curve, the greater the probability the curve would progress. The PHV is reached when the triradiate cartilage is still open; thus, it is important radiographs include the entire pelvis.

Sanders et al. [47] used Tanner-Whitehouse-III staging on hand radiographs to predict the period of rapid curve progression (curve acceleration phase ["CAP"]). Their findings are interesting, because they demonstrated patients who are Risser 0 may have different estimated CAP scores, 
which resulted in substantially different rates of progression. However, all patients who are Risser 0 may not have the same likelihood of progression: patients whose TannerWhitehouse-III stage is before the CAP are at higher risk than those beyond the CAP. Thus, a larger study may yield helpful information pertaining to the need for bracing immature patients and may in fact allow better analysis of bracing studies [45].

The natural history of the untreated patient with scoliosis may involve curve progression and lead to spine surgery. The rationale for surgery is based on evidence supporting morbidity unrelated to the musculoskeletal system as curve magnitude increases [33, 36, 37, 56]. Moderate and severe thoracic curves are associated with reduced vital capacity and total lung capacity [20, 21, 27, 48]. Untreated adolescent patients with major scoliotic curves have a mortality rate slightly higher than the general population of the same age [56]. The mechanism believed responsible for respiratory failure in idiopathic scoliosis is alveolar hypoventilation, potentially caused by decreased lung volume, increased elastic load in the thoracic cage, and impaired respiratory muscle function [21, 26]. The literature regarding pulmonary function after bracing remains controversial. Some studies demonstrate total lung capacity and forced expiratory volume reduced to $80 \%$ of prebracing level [41, 50]. However, Korovessis et al. [26] analyzed pulmonary function in 30 patients with idiopathic scoliosis treated with continuous wearing of a Boston brace and demonstrated substantial yet reversible reduction in vital capacity, forced vital capacity, functional residual capacity, and residual volume over 2 years.

Long-term follow up of patients with idiopathic scoliosis has demonstrated more thoracic and lumbar back pain and degenerative disc disease [8, 54]. Danielsson et al. [8] followed 127 patients 22 years after brace treatment and found degenerative lumbar disc changes were more common than in control subjects. Additionally, brace-treated patients had more back pain than the control group; however, there was minimal functional impairment or impact on daily life. Similarly, Weinstein et al. [54] found, in a 50-year follow up of 117 untreated patients with idiopathic scoliosis, $61 \%$ of patients had low back pain, although nearly $70 \%$ of those patients reported little or moderate back pain and with little physical impairment. Haefeli et al. [17], in their review of 121 patients with idiopathic scoliosis treated nonoperatively and followed over an average of 23 years, reported substantially more pain in patients with curves greater than $45^{\circ}$ compared with those whose curves were smaller. This suggested curve size, rather than treatment, predicted back pain in nonoperatively treated patients.

\section{Bracing}

A brace is designed to apply an external force to the trunk during the adolescent growth phase to prevent progression. As demonstrated subsequently, there are a myriad of brace treatments available, differing in fabrication, area of curve treatment, duration of wear, and wear protocols (Table 1).

\section{Brace Types}

The Milwaukee brace [30] is a cervico-thoracic-lumbarsacral orthosis developed in the 1940s. It is used for thoracic and double curves. It consists of a plastic pelvic section with an anterior and two posterior uprights connected superiorly by a neck ring with a throat mold anteriorly and occipital pads posteriorly or a plastic contoured low-profile neck ring; corrective pads are also used. The Milwaukee brace is prescribed for full-time wear with time out for sports and extracurricular activities. Given the stigma attached to this brace and the availability of other effective braces, the use of this brace is limited.

Table 1. Bracing studies using different brace types

\begin{tabular}{|c|c|c|c|c|}
\hline Study & Type of brace & $\begin{array}{l}\text { Number of } \\
\text { patients }\end{array}$ & $\begin{array}{l}\text { Average initial } \\
\text { curve (degrees) }\end{array}$ & Conclusion \\
\hline $\begin{array}{l}\text { Lonstein and Winter, } \\
1994[30]\end{array}$ & Milwaukee & 1020 & $30-35$ & $\begin{array}{l}\text { Immediate bracing for greater than } 25^{\circ} \text { and Risser } 0 \\
\text { prevents curve progression }\end{array}$ \\
\hline Price et al., 1997 [39] & Charleston & 139 & $25-49$ & $\begin{array}{l}66 \% \text { improved or less than } 5^{\circ} \text { change with brace; } \\
\text { helps in preventing curve progression }\end{array}$ \\
\hline Katz and Durrani, 2001 [24] & Boston & 51 & $36-45$ & $\begin{array}{l}61 \% \text { did not progress greater than } 5^{\circ} \text { from onset of } \\
\text { brace use to discontinuation }\end{array}$ \\
\hline D’Amato et al., 2001 [7] & Providence & 102 & 27 & $\begin{array}{l}61 \% \text { to } 79 \% \text { success rate; the Providence brace is } \\
\text { effective in curves less than } 35^{\circ}\end{array}$ \\
\hline Coillard et al., 2007 [6] & Spine-Cor & 249 & $24-40$ & $\begin{array}{l}\text { Spine-Cor brace able to prevent progression of curve } \\
\text { in } 60 \% \text { of patients }\end{array}$ \\
\hline
\end{tabular}


The Wilmington brace [18] is a TLSO (thoracic-lumbarsacral orthosis) type of brace. It was designed by G. Dean MacEwen to improve patient compliance by making the brace less bulky and more lightweight as compared with the Milwaukee brace. It is a custom-made plastic underarm TLSO fabricated with several plastics, the most common being Orthoplast. It is designed as a body jacket, which opens in the front and is easily removable. It is held closed with adjustable Velcro straps. Corrective molds are fabricated into the plastic of the body jacket. The Wilmington brace is typically prescribed for full-time wear (23 hours/ day), although some studies indicate 12 to 16 hours a day is satisfactory for curves measuring $40^{\circ}$ or less [1].

The Boston brace [35] was developed in the 1970s at Harvard University. It is also a TLSO-type brace and is made from prefabricated polypropylene pelvic module with a soft foam polyethylene lining. Modules are designed with lumbar flexion. The Boston brace can be used to treat all scoliosis; however, it is recommended to be fitted with the Boston Milwaukee brace superstructure when a thoracic curve has an apex above $\mathrm{T}-10$. The Boston brace is a full-time brace.

The Dynamic Spine-Cor brace [6], developed in 19921993, uses a specific Corrective Movement dependent on the type of the curve. The curve-specific Corrective Movement is performed, and the brace is applied according to definitions contained in the Spine-Cor Assistant software. To be effective and to obtain a neuromuscular integration, the brace must maintain and amplify the corrective movement over time. The brace must be worn 20 hours a day for a minimum of 18 months to create a neuromuscular integration of the Corrective Movement through active biofeedback. Generally, the brace is stopped at skeletal maturity (at least Risser 4).

The Charleston brace [53] is a custom-molded spinal orthosis that holds the patient in an overcorrected position. The patient is casted supine in a bending position opposite the curvature while corrective force is applied at the apse of the curve. This brace is a nighttime brace only.

The Providence brace [7] was developed when it was observed that substantial correction of scoliotic curves could be achieved using an acrylic frame to apply direct corrective forces to the patient. The brace can be used to treat all single and double curves. The frame was originally developed to demonstrate radiographic supine spinal flexibility for preoperative planning. The frame works by the application of controlled, direct, lateral, and rotational forces on the trunk to move the spine toward the midline or beyond the midline. A plaster impression of the patient is taken on the frame with corrective forces applied to the spine. The brace is now fabricated using computer-aided design and manufacturing techniques. The brace is fabricated of polypropylene plastic from measurements or a plaster impression. The Providence brace is a nighttimeonly type of brace.

\section{Bracing Efficacy}

Defining "success" from brace treatment of scoliosis can be a challenge. The majority of the literature uses curve progression of more than $5^{\circ}$ before skeletal maturity as a benchmark for bracing failure rather than spine surgery [49]. Some use $10^{\circ}$ of curve progression or preventing the curve from reaching $45^{\circ}$ at skeletal maturity [42].

To compare the effectiveness of various braces, standardized research protocols are needed. The variability defining success of brace treatment in idiopathic scoliosis was addressed by Richards et al. and the SRS Committee on Bracing and Nonoperative Management [42] in an attempt to standardize parameters for effective and reliable comparisons of bracing studies. The recommendations for bracing study inclusion were patients 10 years or older, Risser sign 0 to 2 , initial curve magnitude of $25^{\circ}$ to $40^{\circ}$, and no prior treatment at the initiation of brace treatment. The outcome data should be determined from the percentage of patients with: less than $5^{\circ}$ or greater than $6^{\circ}$ of progression at maturity, curves exceeding $45^{\circ}$ at maturity, and progression resulting in the recommendation for surgery. Bracing studies should have a minimum of 2 years follow up beyond skeletal maturity. The first study to use these criteria determined a brace should prevent progression in $70 \%$ of patients to be considered effective [19]. Patient compliance, subjective or objective, is not factored into the analysis of the data. Regardless of the recommended standardized parameters, the goal of bracing idiopathic curves remains consistent: control the curve, prevent progression, and avoid surgical intervention.

Although some of the new studies are based on the SRS guidelines for bracing studies, others are not. Hence, the results of different types of bracing are varied (Table 2). Several studies have compared full-time bracing [8, 13, 18]. Lonstein and Carlson [29] observed, in 1020 patients treated with the Milwaukee brace for adolescent idiopathic scoliosis, $78 \%$ had improvement of $1^{\circ}$ to $4^{\circ}$ when the brace was discontinued. Twenty-two percent required surgery. The rates of failure were lower than in previous series for patients with curves between $20^{\circ}$ and $39^{\circ}$. Bassett et al. [2] reported 75 patients treated with the Wilmington brace with follow up over 2 years 6 months. The average curve was $20^{\circ}$ to $39^{\circ}$ at Risser 0 or 1 . The magnitude of the curves was reduced by $50 \%$ with initial brace application. There was some loss of correction $(28 \%)$ with removal of brace on subsequent follow up; however, only $11 \%$ of patients needed surgery. They concluded the Wilmington brace favorably altered the natural history of $20^{\circ}$ to $39^{\circ}$ 
Table 2. Studies comparing different braces

\begin{tabular}{|c|c|c|c|c|c|}
\hline Study & $\begin{array}{l}\text { Type of } \\
\text { brace }\end{array}$ & Comparison & $\begin{array}{l}\text { Number of } \\
\text { patients }\end{array}$ & $\begin{array}{l}\text { Average initial } \\
\text { curve }\end{array}$ & Conclusion \\
\hline \multirow{3}{*}{$\begin{array}{l}\text { Nachemson and Peterson, } \\
1995 \text { [32] }\end{array}$} & \multirow[t]{3}{*}{ TLSO } & Total & 286 & \multirow[t]{3}{*}{$25^{\circ}-35^{\circ}$} & \multirow[t]{3}{*}{ Brace prevented progression of curve } \\
\hline & & Observation & 129 & & \\
\hline & & Brace & 111 & & \\
\hline \multirow{5}{*}{$\begin{array}{l}\text { Allington and Bowen, } 1996 \\
\text { [1] }\end{array}$} & \multirow[t]{5}{*}{ Wilmington } & Total & 188 & \multirow[t]{2}{*}{$<30^{\circ}$} & \multirow{5}{*}{$\begin{array}{l}\text { The difference in progression between full- } \\
\text { time } \\
\text { and part-time bracing was not significant }\end{array}$} \\
\hline & & Full-time & 36 & & \\
\hline & & Part-time & 32 & \multirow[t]{3}{*}{$30^{\circ}-40^{\circ}$} & \\
\hline & & Full-time & 62 & & \\
\hline & & Part-time & 17 & & \\
\hline \multirow[t]{3}{*}{ Katz et al., 1997 [25] } & Total & & 319 & - & \multirow{3}{*}{$\begin{array}{l}\text { Boston brace more effective than Charleston } \\
\text { in } \\
\text { preventing curve progression }\end{array}$} \\
\hline & Charleston & & 166 & $32.9^{\circ}$ & \\
\hline & Boston & & 153 & $33.9^{\circ}$ & \\
\hline \multirow[t]{4}{*}{ Howard et al., 1998 [18] } & Total & & 170 & & \multirow{4}{*}{$\begin{array}{l}\text { TLSO superior in preventing curve } \\
\text { progression }\end{array}$} \\
\hline & TLSO & & 45 & & \\
\hline & Charleston & & 95 & & \\
\hline & Milwaukee & & 30 & & \\
\hline \multirow[t]{4}{*}{ Karol, 2001 [22] } & Total & & 117 & & Boston, Charleston no difference \\
\hline & Milwaukee & & 10 & & \multirow{3}{*}{$\begin{array}{l}\text { Insufficient numbers for Milwaukee } \\
\text { comparison }\end{array}$} \\
\hline & Charleston & & 53 & $33.1^{\circ}$ & \\
\hline & Boston & & 54 & & \\
\hline \multirow[t]{3}{*}{ Gepstein et al., 2002 [13] } & Total & & 122 & & \multirow{3}{*}{$\begin{array}{l}\text { Both braces are equally effective; no } \\
\text { significant } \\
\text { difference was found between them }\end{array}$} \\
\hline & Charleston & & 85 & $20^{\circ}-39^{\circ}$ & \\
\hline & TLSO & & 37 & & \\
\hline \multirow{3}{*}{$\begin{array}{l}\text { Danielsson et al., } 2007 \text { [8] } \\
\quad(\mathrm{SRS}+)\end{array}$} & Total & & 106 & - & \multirow[t]{3}{*}{ Bracing more effective than observation } \\
\hline & Boston & & 41 & $31.9^{\circ}$ & \\
\hline & Observation & & 65 & $39.4^{\circ}$ & \\
\hline \multirow{3}{*}{$\begin{array}{l}\text { Janicki et al., } 2007 \text { [19] } \\
\quad(\text { SRS +) }\end{array}$} & Total & & 83 & - & \multirow{3}{*}{$\begin{array}{l}\text { Providence brace is superior in preventing } \\
\text { progression }\end{array}$} \\
\hline & TLSO & & 48 & $33.6^{\circ}$ & \\
\hline & Providence & & 35 & $33.7^{\circ}$ & \\
\hline
\end{tabular}

TLSO $=$ thoracic-lumbar-sacral orthosis; SRS = Scoliosis Research Society.

curves. Katz et al. [25] reviewed 51 patients who had average curves sizes of $36^{\circ}$ to $45^{\circ}$ treated with the Boston brace. Treatment was successful in $61 \%$ of patients, although $16 \%$ progressed more than $5^{\circ}$ and $31 \%$ required surgery. Coillard et al. [6] reported results of 170 patients treated with the Spine-Cor brace. Fifty-nine percent of patients were treated successfully, whereas $23 \%$ required surgery. Furthermore, $95.7 \%$ of patients treated in the brace stabilized or corrected the end of bracing Cobb angle up to 2 years after bracing. They concluded the Spine-Cor brace was effective for treatment of adolescent idiopathic scoliosis. However, as a result of the paucity of literature on the Spine-Cor brace, future studies are needed to confirm these results. Despite success with the Milwaukee, Wilmington, Spine-Cor, and Boston braces, at present none is demonstrably superior to the others with regard to treatment success, curve progression, or need for surgery.
However, part-time bracing studies using the Providence and Charleston brace have also been compared with full-time bracing models with equivalent or superior results (Table 2) [19]. Price et al. [39] reported the results with the Charleston brace in 98 patients in which $63 \%$ had excellent results and, overall, $85 \%$ curves had acceptable results. Curve correction was $87 \%$ for major curves and $33 \%$ for compensatory/secondary curves. Thirteen percent of curves progressed more than $5^{\circ}$ and $1 \%$ of patients required surgery. Trivedi and Thomson [52] reported on 42 patients treated with the Charleston brace over a period of 10 years. Patients were Risser 0 or 1 and were followed a mean of 3.3 years after brace discontinuation. Average age at the start of bracing was 12.5 years and the average curve was $30.3^{\circ}$ (range, $25^{\circ}-40^{\circ}$ ). Bracing was successful preventing progression of the curves in $60 \%$ of patients. Thoracic curves had the 
same success as thoracolumbar and lumbar curves. The authors concluded the Charleston brace was effective preventing progression of the curve.

Using the Providence brace, D'Amato et al. [7] reported in-brace correction of $96 \%$ for major curves and $98 \%$ for minor curves. Seventy-four percent of patients did not progress more than $5^{\circ}$, whereas $26 \%$ of patients progressed more than $6^{\circ}$ or went on to have surgery. Seventy-six percent of patients with curve apices between T8 and L1 had successful outcomes. Overall $63 \%$ of thoracic curves, $65 \%$ of double curves, $94 \%$ of lumbar curves, and $93 \%$ of thoracolumbar curves were treated successfully using the Providence brace.

This may in fact be purely a reflection of compliance; it is much more tolerable for most adolescents to wear a brace that they are not required to wear to school. Currently, the literature supports initiating nighttime bracing for curves measuring less than $35^{\circ}$ with an apex below T9, although centers with experience with these braces may choose to expand the indications [14, 19, 27, 33-35]. Hence, future studies, like the Level 1 BrAIST study [53], will be needed to compare full-time versus part-time bracing using SRS guidelines to determine efficacy of each bracing model to prevent progression of curvature and improve function.

\section{Bracing Difficulties}

Multiple factors can be obstacles to successful brace treatment. Poor compliance with wear schedules is a major recurring theme in the braced patient, particularly males. Karol [22] found only $38 \%$ of males were compliant with brace wear, and $74 \%$ progressed $6^{\circ}$ with nearly half reaching a surgical threshold of $50^{\circ}$. Immature Risser status related to both progression and surgery with greater than $80 \%$ progressing a minimum $6^{\circ}$ and half reaching surgery. Similarly, $55 \%$ of curves measuring greater than $30^{\circ}$ at brace prescription progressed to surgery or greater than $50^{\circ}$. Yrjonen et al. [59] supported these results finding 35\% of braced males were noncompliant. However, although compliant males progressed greater than $5^{\circ} 10 \%$ more frequently than the females $(21 \%)$, they concluded brace treatment for idiopathic scoliosis was beneficial for both genders.

Curve magnitude correlates with curve progression; thus, larger curves are more likely to progress than smaller curves. Likewise, the probability brace treatment will prevent curve progression is inversely proportional to the initial size of the curve $[11,25,30]$. Although brace treatment limits curve progression for curves larger than $35^{\circ}$, success has been less predictable compared with curves between $20^{\circ}$ and $35^{\circ}[1,11,25,30]$.
Bracing success is similar to any prescribed treatment in orthopaedics; it relies on patient compliance. Although casts are not easily removable, braces are easily removed, not surprising given the negative cosmetic appearance, which fosters poor self-esteem and body image, as well as functional discomfort resulting from pressure points, irritation in hot weather, and restriction of movement $[5,33]$. The discomfort caused by the external biomechanical forces applied by a brace, in an effort to alter spine growth, is determined by brace characteristics such as size, location, and thickness of the pads; tension of the straps; molding; and stiffness of the brace. It is these characteristics that cause bracing in the overweight patient to be ineffective and lead to increased curve progression compared with patients who are not overweight [31, 35]. Brace compliance was potentially responsible for the disparity of success between males and females treated with bracing [22, 59] and may explain the similar results of noncompliant patients with the natural history. Numerous studies have demonstrated compliant brace wear leads to successful results, yet much of the data, as acknowledged by the authors, is subjective based on incomplete assessments of compliance such as office notes, questionnaires, or phone or office interviews [22, 30, 34, 58]. Thus, this has led some to doubt the efficacy of bracing and the need for objective compliance measures [51].

To answer the question of compliance, objective compliance measures using temperature sensor loggers and pressure transducers have been developed to ascertain compliance [24, 33]. These authors used temperature data loggers at the brace-skin interface to measure time in the brace and found patients overestimated their time in brace nearly $150 \%$. Patient compliance was best in 10-year-old patients $(84 \%)$ compared with 12-year-old patients $(77 \%)$ and 14-year-old patients $(60 \%)$. However, Rahman was the first to correlate objective compliance with efficacy [40]. A temperature sensor and logger were placed in a Wilmington TLSO brace and patients were monitored for the duration of their treatment. Compliance for those whose curve progressed more than $5^{\circ}$ was $62 \%$, whereas those that did not progress showed $85 \%$ compliance, indicating patient compliance improves the chance for a successful result.

\section{Treatment Recommendations}

Brace treatment for idiopathic scoliosis in the skeletally immature child remains the only effective modality limiting curve progression and the potential need for surgical intervention $[1,11,12,32,39,43]$. Current recommendations from the SRS include the initiation of brace treatment in skeletally immature patients who present with curves 
greater than $30^{\circ}$ on initial presentation or in patients who progress greater than $10^{\circ}$ to a magnitude greater than $25^{\circ}$ [42]. Braces are usually worn 18 to 23 hours a day, although evidence exists demonstrating the effectiveness part-time or nighttime bracing to address patient compliance issues [7, 11, 16, 39, 43]. Part-time or nighttime bracing (Charleston, Providence) may be effective for curves less than $35^{\circ}$; however, curves greater than $35^{\circ}$ often require full-time bracing to reliably limit curve progression. Bracing should continue until growth has stopped, indicated by unchanged height measured consecutively 6 months apart, Risser sign 4 (females) or 5 (males), postmenarchal 18 to 24 months, or skeletal maturity on bone age determination [49]. Although Karol has stated bracing in boys should be continued until Risser 5 as a result of the prolonged growth period during the Risser 4 phase, $46 \%$ of her patients had curves progress to surgical correction despite brace wear [23]. She found nearly $80 \%$ of curves will progress when not braced compared with similarly braced patients and are four times as likely to require spinal instrumentation and fusion, whereas compliant patients will show minimal progression and most likely not require surgery. Bracing success is measured by preventing curve progression on standing radiographs and the avoidance of surgical management. Inadequate time prescribed in the brace and a poor-fitting brace certainly will lead to poor results and are beyond control of the patient. However, compliance appears to be the greatest concern for any treating physician and the primary cause for poor results from brace treatment. Additionally, bracing in males and obese, skeletally mature, and nonidiopathic patients is less effective. Long-term follow up suggests bracing may be beneficial into adulthood, improving life expectancy, patient satisfaction, and function, although there is a higher incidence of back pain $[9,17,55]$.

At our institution, Providence bracing is initiated for curves between $25^{\circ}$ and $35^{\circ}$ in patients with substantial growth remaining. Occasionally, patients seen before peak height velocity with curves that are already becoming cosmetically objectionable (ie, thoracolumbar curves) will be braced for curves over $20^{\circ}$, although this is a relative indication. For patients presenting with larger curves, or for patients who progress with nighttime-only bracing, we prefer to add a TLSO for daytime use (total 18-20 hours per day). Assuming appropriate in-brace correction in the Providence brace, the addition of a Boston brace should be additive in terms of forces applied to the spine as opposed to changing brace treatment completely. We have found the combination of braces is well tolerated, putting pressure on slightly different locations to avoid brace irritation. Bracing continues until growth stops or curve progression cannot be controlled and spine surgery is indicated. For successful treatment, this is usually through Risser 4 in girls and Risser 5 in boys. A review of patients followed to maturity at our institution is underway to determine the effectiveness of our combined brace protocol.

\section{Discussion}

The natural history of idiopathic scoliosis has been well documented throughout the literature. Left untreated, the younger the patient (i.e., the amount of skeletal growth remaining) and the larger the curve at the initiation of bracing, the greater the chance of curve progression, thus necessitating surgery. Brace treatment with full-time (Boston, Wilmington, and Milwaukee) or nighttime (Charleston and Providence) bracing continues to be the only efficacious mode of nonoperative treatment in idiopathic scoliosis.

To date, a major criticism of the bracing literature remains the absence of a prospective, randomized study to determine the efficacy of brace treatment. The ongoing Level-1 BrAIST study will hopefully address the limitations of prior work. Nonetheless, assumptions can be made based on the existing literature. Newer methods of determining the period of rapid curve progression may help guide treatment decisions. The availability of successful nighttime treatment regimens has the potential improve compliance and, thus, success rates. However, brace treatment demands participation from the patient and their support network; parents, family, and friends; the orthopaedist; and the orthotist. Each has an integral part in fostering bracing success and potentially is the difference in preventing curve progression and the need for spine surgery.

\section{References}

1. Allington NJ, Bowen JR. Adolescent idiopathic scoliosis: treatment with the Wilmington brace. A comparison of full-time and part-time use. J Bone Joint Surg Am. 1996;78:1056-1062.

2. Bassett GS, Bunnell WP, MacEwen GD. Treatment of idiopathic scoliosis with the Wilmington brace. Results in patients with a twenty to thirty-nine-degree curve. J Bone Joint Surg Am. 1986;68:602-605.

3. Bunnell WP. The natural history of idiopathic scoliosis. Clin Orthop Relat Res. 1988;229:20-25.

4. Bunnell WP. The natural history of idiopathic scoliosis before skeletal maturity. Spine. 1986;11:773-776.

5. Clayson D, Luz-Alterman S, Cataletto MM, Levine DB. Longterm psychological sequelae of surgically versus nonsurgically treated scoliosis. Spine. 1987;12:983-986.

6. Coillard C, Vachon V, Circo AB, Beausejour M, Rivard CH. Effectiveness of the SpineCor brace based on the new standardized criteria proposed by the scoliosis research society for adolescent idiopathic scoliosis. J Pediatr Orthop. 2007;27:375379.

7. D'Amato CR, Griggs S, McCoy B. Nighttime bracing with the Providence brace in adolescent girls with idiopathic scoliosis. Spine. 2001;26:2006-2012. 
8. Danielsson AJ, Hasserius R, Ohlin A, Nachemson AL. A prospective study of brace treatment versus observation alone in adolescent idiopathic scoliosis: a follow-up mean of 16 years after maturity. Spine. 2007;32:2198-2207.

9. Danielsson AJ, Romberg K, Nachemson AL. Spinal range of motion, muscle endurance, and back pain and function at least 20 years after fusion or brace treatment for adolescent idiopathic scoliosis: a case-control study. Spine. 2006;31:275-283.

10. Dickson RA. Spinal deformity-adolescent idiopathic scoliosis. Nonoperative treatment. Spine. 1999;24:2601-2606.

11. Emans JB, Kaelin A, Bancel P, Hall JE, Miller ME. The Boston bracing system for idiopathic scoliosis. Follow-up results in 295 patients. Spine. 1986;11:792-801.

12. Fernandez-Feliberti R, Flynn J, Ramirez N, Trautmann M, Alegria M. Effectiveness of TLSO bracing in the conservative treatment of idiopathic scoliosis. J Pediatr Orthop. 1995; 15:176181.

13. Gepstein R, Letner Y, Zohar E, Angel I, Shabat S, Pekarsky I, Friesem T, Folman Y, Katz A, Fredman B. Effectiveness of the Charleston bending brace in the treatment of single-curve idiopathic scoliosis. J Pediatr Orthop. 2002;22:84-87.

14. Goldberg CJ, Dowling FE, Hall JE, Emans JB. A statistical comparison between natural history of idiopathic scoliosis and brace treatment in skeletally immature adolescent girls. Spine. 1993;18:902-908.

15. Goldberg CJ, Moore DP, Fogarty EE, Dowling FE. Adolescent idiopathic scoliosis: the effect of brace treatment on the incidence of surgery. Spine. 2001;26:42-47.

16. Green NE. Part-time bracing of adolescent idiopathic scoliosis. J Bone Joint Surg Am. 1986;68:738-742.

17. Haefeli M, Elfering A, Kilian R, Min K, Boos N. Nonoperative treatment for adolescent idiopathic scoliosis: a 10 - to 60 -year follow-up with special reference to health-related quality of life. Spine. 1998;31:355-366; discussion 367.

18. Howard A, Wright JG, Hedden D. A comparative study of TLSO, Charleston, and Milwaukee braces for idiopathic scoliosis. Spine. 1998;23:2404-2411.

19. Janicki JA, Poe-Kochert C, Armstrong DG, Thompson GH. A comparison of the thoracolumbosacral orthoses and providence orthosis in the treatment of adolescent idiopathic scoliosis: results using the new SRS inclusion and assessment criteria for bracing studies. J Pediatr Orthop. 2007;27:369-374.

20. Jones RS, Kennedy JD, Hasham F, Owen R, Taylor JF. Mechanical inefficiency of the thoracic cage in scoliosis. Thorax. 1981;36:456-461.

21. Kafer ER. Respiratory and cardiovascular functions in scoliosis. Bull Eur Physiopathol Respir. 1977;13:299-321.

22. Karol LA. Effectiveness of bracing in male patients with idiopathic scoliosis. Spine. 2001;26:2001-2005.

23. Karol LA, Johnston CE 2nd, Browne RH, Madison M. Progression of the curve in boys who have idiopathic scoliosis. $J$ Bone Joint Surg Am. 1993;75:1804-1810.

24. Katz DE, Durrani AA. Factors that influence outcome in bracing large curves in patients with adolescent idiopathic scoliosis. Spine. 2001;26:2354-2361.

25. Katz DE, Richards BS, Browne RH, Herring JA. A comparison between the Boston brace and the Charleston bending brace in adolescent idiopathic scoliosis. Spine. 1997;22:1302-1312.

26. Korovessis P, Filos KS, Georgopoulos D. Long-term alterations of respiratory function in adolescents wearing a brace for idiopathic scoliosis. Spine. 1996;21:1979-1984.

27. Levine DB. Pulmonary function in scoliosis. Orthop Clin North Am. 1979;10:761-768.

28. Lonstein JE. Scoliosis: surgical versus nonsurgical treatment. Clin Orthop Relat Res. 2006;443:248-259.
29. Lonstein JE, Carlson JM. The prediction of curve progression in untreated idiopathic scoliosis during growth. J Bone Joint Surg Am. 1984;66:1061-1071.

30. Lonstein JE, Winter RB. The Milwaukee brace for the treatment of adolescent idiopathic scoliosis. A review of one thousand and twenty patients. J Bone Joint Surg Am. 1994;76:1207-1221.

31. Moreland M. Bracing in scoliosis. Curr Opin Orthop. 1998;9:66-71.

32. Nachemson AL, Peterson LE. Effectiveness of treatment with a brace in girls who have adolescent idiopathic scoliosis. A prospective, controlled study based on data from the Brace Study of the Scoliosis Research Society. J Bone Joint Surg Am. 1995;77:815-822.

33. Nicholson GP, Ferguson-Pell MW, Smith K, Edgar M, Morley T. The objective measurement of spinal orthosis use for the treatment of adolescent idiopathic scoliosis. Spine. 2003;28:2243-2250; discussion 2250-2251.

34. Noonan KJ, Weinstein SL, Jacobson WC, Dolan LA. Use of the Milwaukee brace for progressive idiopathic scoliosis. $J$ Bone Joint Surg Am. 1996;78:557-567.

35. O'Neill PJ, Karol LA, Shindle MK, Elerson EE, BrintzenhofeSzoc KM, Katz DE, Farmer KW, Sponseller PD. Decreased orthotic effectiveness in overweight patients with adolescent idiopathic scoliosis. J Bone Joint Surg Am. 2005; 87:1069-1074.

36. Pehrsson K, Larsson S, Oden A, Nachemson A. Long-term follow-up of patients with untreated scoliosis. A study of mortality, causes of death, and symptoms. Spine. 1992;17:1091-1096.

37. Pehrsson K, Nachemson A, Olofson J, Strom K, Larsson S. Respiratory failure in scoliosis and other thoracic deformities. A survey of patients with home oxygen or ventilator therapy in Sweden. Spine. 1992;17:714-718.

38. Picault C, deMauroy JC, Mouilleseaux B, Diana G. Natural history of idiopathic scoliosis in girls and boys. Spine. 1986;11:777-778.

39. Price CT, Scott DS, Reed FR Jr, Sproul JT, Riddick MF. Nighttime bracing for adolescent idiopathic scoliosis with the Charleston Bending Brace: long-term follow-up. J Pediatr Orthop. 1997; 17:703-707.

40. Rahman T, Bowen JR, Takemitsu M, Scott C. The association between brace compliance and outcome for patients with idiopathic scoliosis. J Pediatr Orthop. 2005;25:420-422.

41. Refsum HE, Naess-Andresen CF, Lange JE. Pulmonary function and gas exchange at rest and exercise in adolescent girls with mild idiopathic scoliosis during treatment with Boston thoracic brace. Spine. 1990;15:420-423.

42. Richards BS, Bernstein RM, D'Amato CR, Thompson GH. Standardization of criteria for adolescent idiopathic scoliosis brace studies: SRS Committee on Bracing and Nonoperative Management. Spine. 2005;30:2068-2075; discussion 2076-2077.

43. Rowe DE. The Scoliosis Research Society Brace Manual. Milwaukee, WI: Scoliosis Research Society; 1998:1-9.

44. Rowe DE, Bernstein SM, Riddick MF, Adler F, Emans JB, Gardner-Bonneau D. A meta-analysis of the efficacy of nonoperative treatments for idiopathic scoliosis. J Bone Joint Surg Am. 1997;79:664-674.

45. Sanders JO. Maturity indicators in spinal deformity. J Bone Joint Surg Am. 2007;89 Suppl 1:14-20.

46. Sanders JO, Browne RH, Cooney TE, Finegold DN, McConnell SJ, Margraf SA. Correlates of the peak height velocity in girls with idiopathic scoliosis. Spine. 2006;31:2289-2295.

47. Sanders JO, Browne RH, McConnell SJ, Margraf SA, Cooney TE, Finegold DN. Maturity assessment and curve progression in girls with idiopathic scoliosis. J Bone Joint Surg Am. 2007;89:64-73.

48. Sevastikoglou JA, Linderholm H, Lindgren U. Effect of the Milwaukee brace on vital and ventilatory capacity of scoliotic patients. Acta Orthop Scand. 1976;47:540-545. 
49. Shaughnessy WJ. Advances in scoliosis brace treatment for adolescent idiopathic scoliosis. Orthop Clin North Am. 2007; 38:469-475.

50. Smyth RJ, Chapman KR, Wright TA, Crawford JS, Rebuck AS. Pulmonary function in adolescents with mild idiopathic scoliosis. Thorax. 1984;39:901-904.

51. Takemitsu M, Bowen JR, Rahman T, Glutting JJ, Scott CB. Compliance monitoring of brace treatment for patients with idiopathic scoliosis. Spine. 2004;29:2070-2074; discussion 2074.

52. Trivedi JM, Thomson JD. Results of Charleston bracing in skeletally immature patients with idiopathic scoliosis. J Pediatr Orthop. 2001;21:277-280.

53. Weinstein SL. Bracing in Adolescent Idiopathic Scoliosis Trial (BrAIST). Available at: www.clinicaltrials.gov. University of Iowa, National Institute of Arthritis and Musculoskeletal and Skin Diseases (NIAMS) 2008. Accessed March 1, 2009.

54. Weinstein SL, Dolan LA, Spratt KF, Peterson KK, Spoonamore MJ, Ponseti IV. Health and function of patients with untreated idiopathic scoliosis: a 50-year natural history study. JAMA. 2003;289:559-567.

55. Weinstein SL, Ponseti IV. Curve progression in idiopathic scoliosis. J Bone Joint Surg Am. 1983;65:447-455.

56. Weinstein SL, Zavala DC, Ponseti IV. Idiopathic scoliosis: longterm follow-up and prognosis in untreated patients. J Bone Joint Surg Am. 1981;63:702-712.

57. Wever DJ, Tonseth KA, Veldhuizen AG, Cool JC, van Horn JR. Curve progression and spinal growth in brace treated idiopathic scoliosis. Clin Orthop Relat Res. 2000;377:169-179.

58. Wiley JW, Thomson JD, Mitchell TM, Smith BG, Banta JV. Effectiveness of the boston brace in treatment of large curves in adolescent idiopathic scoliosis. Spine. 2000;25:23262332.

59. Yrjonen T, Ylikoski M, Schlenzka D, Poussa M. Results of brace treatment of adolescent idiopathic scoliosis in boys compared with girls: a retrospective study of 102 patients treated with the Boston brace. Eur Spine J. 2007;16:393-397. 